\title{
Corrosion and Biocompatibility Assessment of Magnesium Alloys
}

\author{
Puneet Gill $^{1}$, Norman Munroe ${ }^{1}$, Rupak Dua ${ }^{2}$, Sharan Ramaswamy ${ }^{2}$ \\ ${ }^{1}$ Department of Mechanical and Materials Engineering, Florida International University, Florida, USA; ${ }^{2}$ Department of Biomedical \\ Engineering, Florida International University, Florida, USA. \\ Email: pgill001@fiu.edu
}

Received October $12^{\text {th }}, 2011$; revised November $22^{\text {nd }}, 2011$; accepted December $7^{\text {th }}, 2011$

\begin{abstract}
Magnesium due to its good biocompatibility, mechanical properties, necessity in metabolic processes and lightness in weight, is an ideal candidate for biodegradable implants. The major concerns with magnesium and its alloys are that of rapid and non-uniform corrosion. In this investigation, magnesium based binary, ternary and quaternary alloys were studied for their corrosion resistance and biocompatibility. In vitro corrosion resistance of the alloys was studied in accordance with ASTM G 102-89 in phosphate buffered saline (PBS) at $37^{\circ} \mathrm{C}$. The surface morphology of the alloys was studied using scanning electron microscopy (SEM) and the wettability of the alloys was determined by contact angle measurements. Additionally, the cytotoxicity of the leached metal ions on the viability of osteoblast was evaluated bysulforhodamine B (SRB) assay.
\end{abstract}

Keywords: Biodegradable; Corrosion; Biocompatibility; Osteoblast Cells

\section{Introduction}

The demand for better and improved materials for biomedical application is increasing. Recently there has been an increased interest in degradable materials due to superior mechanical (higher tensile strength, Young's modulus and bone-matching density), electrochemical and biological properties over currently used materials. Current metallic biomaterials remain essentially neutral in vivo, serving as permanent fixtures, which in the case of plates, screws and pins, are used to secure serious fractures and thus must be removed by a second surgical procedure after the tissue has healed sufficiently. Repeat surgical procedures increase health costs and morbidity of patients. A considerable amount of research has been focused on traditional biodegradable polymers, ceramics and metals. However, polymer and ceramic biodegradable materials exhibit insufficient mechanical properties and their degradation products may elicit an inflammatory response.

More recently, there has been a resurgence in the use of magnesium as a bioimplant material. Magnesium is the fourth most abundant mineral in human body and is required for more than 325 biochemical reactions. In this investigation, magnesium based alloys were studied for their corrosion and biocompatibility properties.

$\mathrm{Mg}$ alloys generally degrade or corrode in aqueous environment to produce magnesium hydroxide, $\mathrm{Mg}(\mathrm{OH})_{2}$ and hydrogen gas $\left(\mathrm{H}_{2}\right)$. The passivating oxide subsequently retards the rate of corrosion. In the case of magnesium implants, corrosion is also influenced by chlorides, amino acids and dissolved oxygen. Nevertheless, the overall corrosion reaction of magnesium in an aqueous environment can be summarized as follows [1,2]:

$$
\begin{aligned}
& \mathrm{Mg}_{(\mathrm{s})}+\mathrm{H}_{2} \mathrm{O}_{(\text {aq) }} \rightarrow \mathrm{Mg}_{\text {(aq) }}^{2+}+\mathrm{OH}^{-}+\frac{1}{2} \mathrm{H}_{2}+\mathrm{e}^{-} \\
& \text {(anodic reaction) } \\
& \mathrm{H}_{2} \mathrm{O}_{(\text {aq) }}+\mathrm{e}^{-} \rightarrow \frac{1}{2} \mathrm{H}_{2(\mathrm{~g})}+\mathrm{OH}_{(\text {aq) }}^{-}(\text {cathodic reaction) } \\
& \mathrm{Mg}_{(\text {aq) }}^{2+}+2 \mathrm{OH}_{(\text {aq) }}^{-} \rightarrow \mathrm{Mg}(\mathrm{OH})_{2(\mathrm{~s})} \text { (product formation) (3) } \\
& \mathrm{Mg}_{(\mathrm{s})}+2 \mathrm{H}_{2} \mathrm{O}_{(\text {aq) }} \rightarrow \mathrm{Mg}(\mathrm{OH})_{2(\mathrm{~s})}+\mathrm{H}_{2(\mathrm{~g})} \text { (overall reaction) }
\end{aligned}
$$

$\mathrm{Mg}^{2+} / \mathrm{Mg}$ have a standard electrode potential of -2.37 $\mathrm{V}$ at $25^{\circ} \mathrm{C}$, whereas the actual corrosion potential of magnesium is usually $-1.7 \mathrm{~V}$ in dilute chloride solutions. Song et al. reported that the presence of $\mathrm{Cl}^{-}$ions accelerates the electrochemical reaction rate by forming magnesium chloride, which hydrolyses to produce hydrochloric acid in a localized auto-catalytic process [2,3]. On the other hand, Reactions (1) and (2) produce $\mathrm{OH}^{-}$ions in solution, which can be utilized to neutralize dead cells for safe disposal in urine [4]. 


\section{Experimental Procedure}

The degradation rate of magnesium is one of its limitations as a biomaterial. In order to achieve controlled degradation and to preserve mechanical integrity, alloying is an essential step. In this investigation, magnesium alloys were prepared in an ARC furnace by ACI Alloys, Inc. The ingots were casted in a water-cooled copper mould, heat treated at $350^{\circ} \mathrm{C}$ in the furnace and water quenched. Table 1 shows the composition of the alloys in weight percentage (wt\%). The specimens were cut into cubes of dimensions 0.414 " $\times 0.414$ " $\times 0.08$ " using a linear precision saw (ISOMET 4000). Each cube was mounted into epoxy resin with an exposed working area of 0.414 " $\times 0.414$ ". As the samples were water sensitive, the usage of water as a lubricant or water based consumables was avoided during sample preparation.

The surface morphology and qualitative chemical composition of the alloys were assessed using SEM/EDS (JEOL JSM 6330F).

A typical three electrode (working, counter and reference) corrosion cell interphased with a potentiostat was used, in which the implant material (working electrode) was placed in an appropriate deaerated simulated physiological solution, phosphate buffer saline solution (PBS). The potentiodynamic polarization tests were performed in accordance with ASTM: G 102-89 [5] in PBS (pH = 7.2) at $37^{\circ} \mathrm{C}$ employing a $\mathrm{GAMRY}^{\circledR}$ potentiostat (G-750).

Contact angles were obtained using the sessile drop method with a Kyowa contact angle meter model DMCE1 employing three different solvents (water, ethylene-glycol and diiodomethane). The tests were conducted under ambient conditions at various locations on each specimen with sufficient spacing to prevent any interference from previous tests.

The viability of osteoblast cells (ATCC, catalog \# CRL11372) exposed to dissolved ions in PBS after corrosion were assessed by SRB assay. The cells were thawed on receiving and seeded in T-75 tissue culture flasks in culture medium which was made from $89 \%$ base media (Invitrogen, Catalog\# 11039-021), 10\% FBS (ATCC, Catalog\# 30-2020), 1\% Penstrep (ATCC, Cata$\log \# 30-2020$ ) and $0.3 \mathrm{mg} / \mathrm{ml}$ of G418 of the base media. Once the cells were $90 \%$ confluent, in the flask, the cells were trypisinized. $200 \mu \mathrm{l}$ of cell solution (approx 20,000 cells/well) were placed in three 96 well plates. Osteoblast cells in the wells were exposed to three different concentrations of corrosion extract $(10 \%, 50 \%$ and $100 \%)$ over periods of 2, 4 and 7 days. The corrosion extracts were prepared by mixing FBS, penstrep and G418 in the corrosion liquid. The well plates were then placed in an incubator at $37^{\circ} \mathrm{C}$ and $5 \% \mathrm{CO}_{2}$. The viability of the osteoblast cells were assessed at different time points using SRB which was based on the absorbances measured.

\section{Results and Discussions}

Figure 1 illustrates the photomicrograph and the EDS

Table 1. Chemical composition of the alloys (wt\%).

\begin{tabular}{cccc}
\hline $\begin{array}{c}\text { Magnesium } \\
(\mathrm{Mg})\end{array}$ & $\begin{array}{c}\text { Zinc } \\
(\text { Zn) }\end{array}$ & $\begin{array}{c}\text { Calcium } \\
(\mathrm{Ca})\end{array}$ & $\begin{array}{c}\text { Gadolinium } \\
(\mathrm{Gd})\end{array}$ \\
\hline 99 & 1 & - & - \\
98 & 1 & 1 & - \\
90 & 1 & 1 & 8 \\
\hline
\end{tabular}

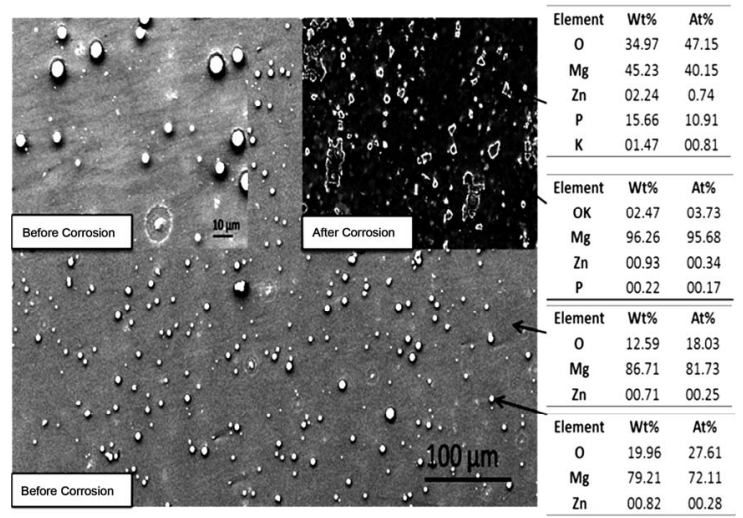

(a)

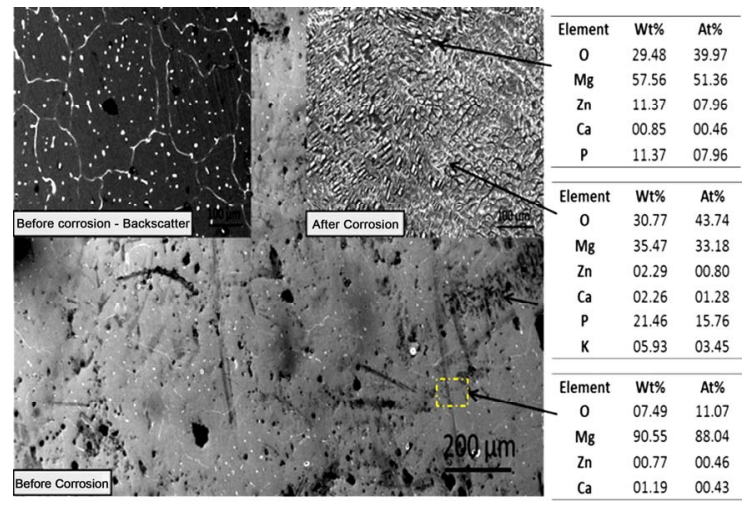

(b)

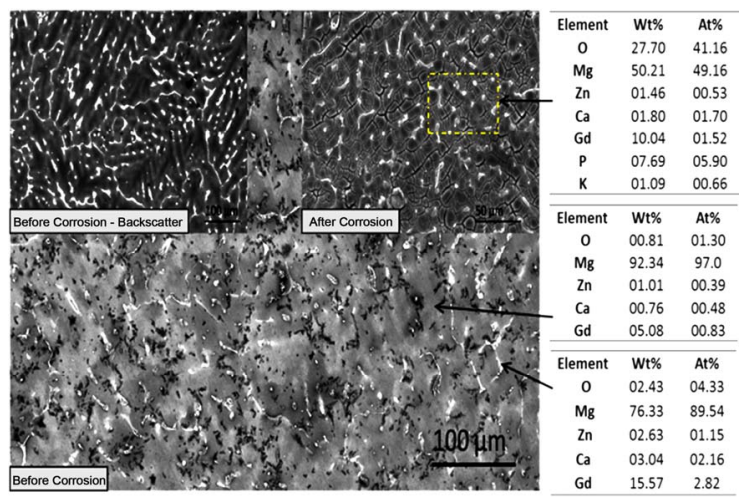

(c)

Figure 1. SEM photomicrographs and EDS analysis before and after corrosion of (a) MgZn; (b) MgZnCa; and (c) MgZnCaGd. 
analysis of mechanically polished as cast alloys. A significant amount of well-dispersed dots $(\sim 5 \mu \mathrm{m})$ were observed on the surface of as-polished MgZn samples (Figure 1(a)). EDS analysis at these spots indicated a higher concentration of oxygen. Preferentially, corrosion occurred in the magnesium rich matrix leaving islands rich in zinc, oxygen and phosphorous (possibly zinc phosphates). The formation of islands could be attributed to the oxides (passivating layer), which partially restricts the penetration of electrolyte. On the other hand, MgZnCa also showed evidence of precipitates (Figure 1(b) white dots, before corrosion) but with grain boundaries that were clearly visible as a result of grain boundary segregation. However, after corrosion, the major difference noted was a higher density of smaller islands on the surface as shown in Figure 1(b). EDS analysis revealed higher con- centrations of zinc, calcium, phosphorous and oxygen (possibly forming a mixture of apatite and zinc phosphate). The photomicrograph of MgZnCaGd illustrated the evidence of rosette-shaped dendrites [6] rich in zinc, calcium and gadolinium (Figure 1(c)). EDS analysis of the alloy after corrosion revealed higher concentrations of zinc, calcium, gadolinium and oxygen (possibly form- ing a mixture of apatite, zinc phosphate and gadolinium oxides). The presence of stress induced cracking was also observed due to preferential dissolution of magnesium.

Figure 2 shows the typical polarization curves for the MgZn, MgZnCa and MgZnCaGd alloys depicting passivation control. The degradation rates obtained for MgZn, MgZnCa and MgZnCaGd, were 23.17, 51.1 and $44.2 \mathrm{~mm} /$ year respectively. The corrosion potential ( $\mathrm{E}_{\text {corr }}$ ) of MgZn was $-1.43 \mathrm{~V}$ followed by MgZnCaGd $(-1.56 \mathrm{~V})$ and MgZnCa $(-1.68 \mathrm{~V})$, indicating that MgZn is least susceptible to corrosion followed by MgZnCaGd and MgZnCa. The addition of zinc and gadolinium therefore improved the corrosion resistance by forming a protective layer on the surface. The rough appearance of the anodic curves was associated with repeated breakdown and regeneration (pitting corrosion) of the passivation layer.

Each alloy exhibited hydrophobic behavior with each of the solvents that were used. The contact angles were 98.0, 95.2 and 93.1 (degree) on MgZn, MgZnCa and MgZnCaGd respectively with water. It was observed that the contact angle decreased moderately with the addition of alloying elements. Table 2 shows acidic (electron acceptor), basic (electron donor) and contact angle parameters in accordance with the Acid-base theory.

Figure 3 shows the optical images of osteoblast cultured for 2, 4 and 7 days in a control and in 10\% extract media. With all the alloys, cell growth occurred with time for both the control and $10 \%$ corrosion extract. However, the numbers of dead cells in $10 \%$ corrosion extract ap- peared to increase after the 4 day period.

A similar trend was obtained for the growth rate of osteoblast cells exposed to $10 \%, 50 \%$ and $100 \%$ corrosion extract fromeach alloy. Figure 4 shows the osteoblast growth rate in corrosion extracts from MgZnCa alloy with time. A steady increase in growth rate was observed in $10 \%$ extract and at day 7 a slight decrease in growth rate was observed. $50 \%$ and $100 \%$ extract: day 2,4 and 7 , a net decrease of $\sim 30 \%$ and $\sim 60 \%$ were observed respecttively.

\section{Conclusion}

Each alloy displayed a different corrosion behavior. MgZn was least susceptible to corrosion followed by MgZnCaGd and MgZnCa with corrosion rates of 23.17, 44.2 and 51.1 $\mathrm{mm} /$ year respectively. MgZn produced islands composed possibly of zinc phosphate as a result of preferential corrosion of the magnesium rich matrix. On the other hand, the corroded surfaces of MgZnCa and MgZnCaGd revealed a mixture of apatite, zinc phosphate, gadolinium and magnesium oxides. The corroded surface of MgZnCaGd showed regions of stress induced cracking as a result of preferential dissolution of magnesium. All alloys exhibited hydrophobic behavior with water, ethylene-glycol and diiodomethane. Osteoblast cell growth in 10\% corrosion extract was not adversely affected. However, corrosion extracts of $50 \%$ and $100 \%$ were found to be toxic



Figure 2. Polarization curves of MgZn, MgZnCa and MgZnCaGd in $\mathrm{PBS}$ at $37^{\circ} \mathrm{C}$, showing passivating behavior.

Table 2. Acidic, basic and contact angle measure by Acidbase theory.

\begin{tabular}{cccc}
\hline Alloy & Acidic $(+)$ & Basic $(-)$ & Contact Angle (degree) \\
\hline MgZn & 0.4 & 0.1 & 98.0 \\
MgZnCa & 0.0 & 2.6 & 95.2 \\
MgZnCaGd & 0.1 & 2.0 & 93.1 \\
\hline
\end{tabular}




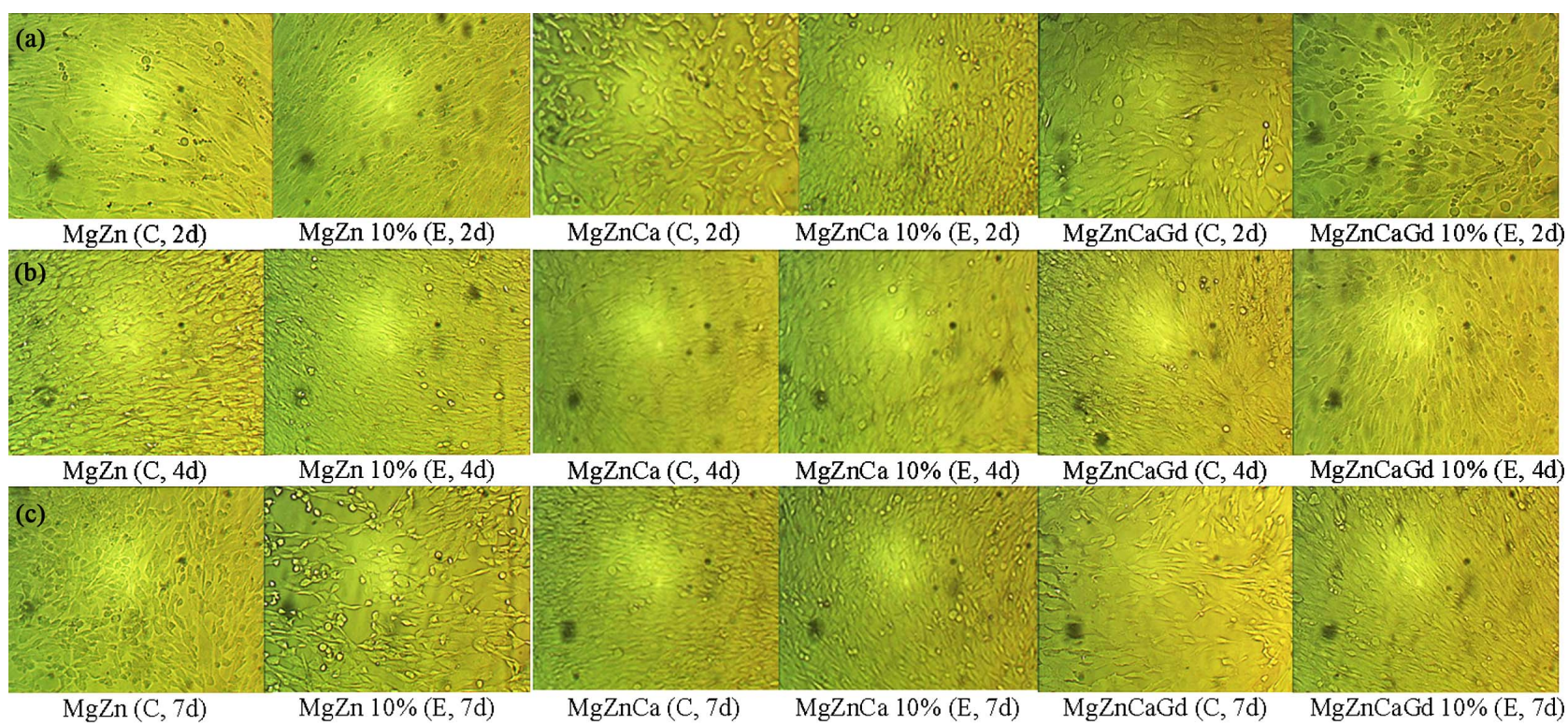

Figure 3. Optical morphologies of osteoblast cells that were cultured in the control (C) and $10 \%$ extract (E) concentrations of MgZn, MgZnCa and MgZnCaGd alloys from potentiodynamic corrosion test runs in PBS for (a) 2 days; (b) 4 days; and (c) 7 days.

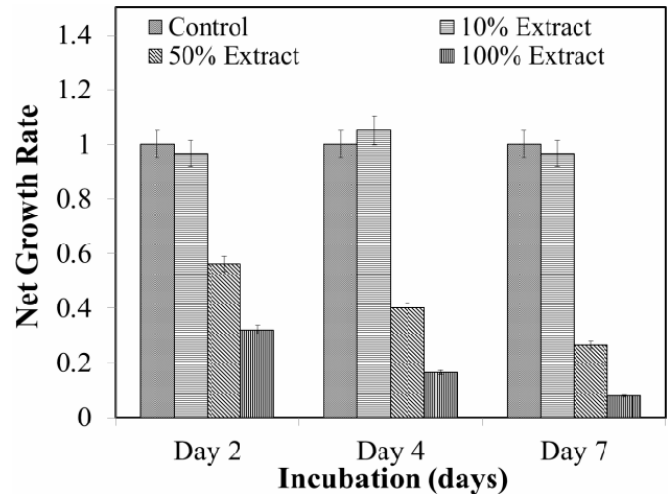

Figure 4. Normazied SRB cuve for MgZnCa.

to the osteoblast cells.

\section{Acknowledgements}

The authors would like to acknowledge Dr. H. T. Lin and Amit Datye from Oak Ridge National Laboratory (ORNL) for their helpful discussions. N. M. would like to acknowledge the financial support from National Institute of General Medical Sciences Award Number SC3GM084816. P. G. acknowledges the Doctoral Evidence Acquisition Fellowship from University Graduate School Florida International University.

\section{REFERENCES}

[1] Y. Wang, C. S. Lim, C. V. Lim, M. S. Yong, E. K. Teo and L. N. Moh, "In Vitro Degradation Behavior of M1A Magnesium Alloy in Protein-Containing Simulated Body Fluid," Materials Science and Engineering C, Vol. 31, No. 8, 2011, pp. 579-587. doi:10.1016/j.msec.2010.11.017

[2] F. Witte, N. Hort, C. Vogt, S. Cohen, K. Ulrich Kainer, R. Willumeit and F. Feyerabend, "Degradable Biomaterials Based on Magnesium Corrosion," Current Options in Solid State and Materials Science, Vol. 12, No. 5-6, 2008, pp. 63-72.

[3] G. L. Song and A. Atrens, "Corrosion Mechanisms of Magnesium Alloys,” Advanced Engineering Materials, Vol. 1, No. 1, 1999, pp. 11-33.

doi:10.1002/(SICI)1527-2648(199909)1:1<11::AID-ADE M11>3.0.CO;2-N

[4] S. Whang, "Article 21-How Does Our Body Maintain Health,” Science and Health Series, Alkalife, 2011.

[5] American Society for Testing and Materials, "Standard Practice for Calculation of Corrosion Rates and Related Information from Electrochemical Measurements," ASTM, West Conshohocken, G102-89, 1999.

[6] Q. Peng, X. Hou, L. Wang, Y. Wu, Z. Cao and L. Wang, "Microstructure and Mechanical Properties of High Performance Mg-Gd Based Alloys," Materials \& Design, Vol. 30, No. 2, 2009, pp. 292-296. 